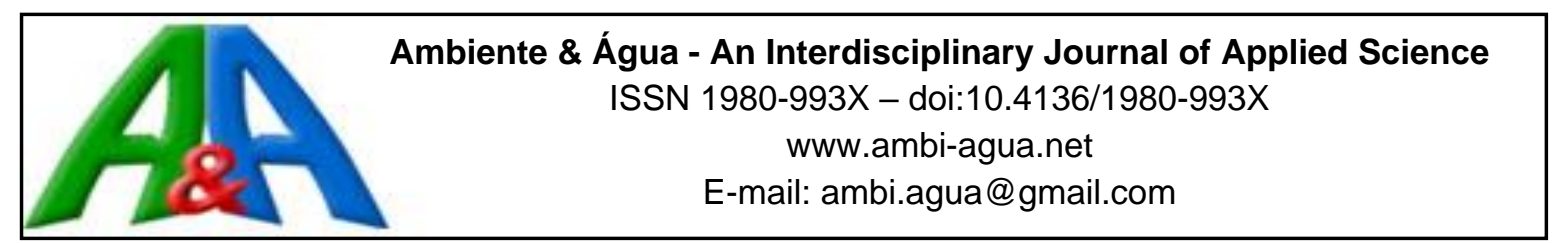

\title{
Temperatura e precipitação: futuros cenários do município de Taubaté, SP, Brasil
}

\author{
doi:10.4136/ambi-agua.1896
}

Received: 2 Sep. 2016; Accepted: 17 Nov. 2016

\author{
Thiago Adriano dos Santos ${ }^{1 *}$; Gilberto Fisch ${ }^{1,2}$ \\ ${ }^{1}$ Universidade de Taubaté (UNITAU), Taubaté, SP, Brasil \\ Programa de Pós-Graduação em Ciências Ambientais \\ ${ }^{2}$ Instituto de Aeronáutica e Espaço (IAE), São José dos Campos, SP, Brasil \\ Departamento de Ciência e Tecnologia Aeroespacial (IAE/DCTA) \\ *Autor correspondente: e-mail: thiagoadrianodossantos@ hotmail.com, \\ fisch.gilberto@gmail.com
}

\section{RESUMO}

Neste trabalho se utilizou um modelo de simulação climática para a região de Taubaté baseado em dados de precipitação e temperatura das simulações do passado, climatologia entre 1961-1990 com as devidas correções com dados observacionais, e de simulação do futuro, intervalos de tempo 2011-2040; 2041-2070 e 2071-2099. Neste cenário futuro resultados apontam um aumento temperatura média anual do ar em $3,6^{\circ} \mathrm{C}$, e um aumento na precipitação acumulada anual em $231 \mathrm{~mm}$, equivalente a aproximadamente $17 \%$ da normal climatológica, para o intervalo de tempo 2071-2099. Em relação à distribuição sazonal, o maior aumento médio mensal de temperatura do ar é esperado na primavera $\left(4,1^{\circ} \mathrm{C}\right)$ e o menor no verão $\left(3,4^{\circ} \mathrm{C}\right)$, enquanto que o maior aumento de precipitação média diária é esperado no verão $(1,1 \mathrm{~mm})$ e o menor aumento na primavera $(0,3 \mathrm{~mm})$. A precipitação diária superior a $1 \mathrm{~mm}$ ao longo do ano deverá aumentar em 5 dias. Apesar do aumento da precipitação a análise do balanço hídrico indica deficit nos meses de agosto e setembro, dada a disparidade entre as entrada e saída de água no território havendo, neste caso, a necessidade de adaptação a um novo cenário social e ambiental.

Palavras-chave: balanço hídrico regional, modelo atmosférico regional, simulação climática.

\section{Temperature and precipitation: future scenarious from Taubaté, SP, Brasil}

\begin{abstract}
This work quantified temperature and precipitation variations in the region of Taubate using historic precipitation data and temperature simulations (climatology from 1961 to 1990). Corrections were made based on the observational data, and simulations of future time intervals (2011-2040, 2041-2070, 2071-2099) using a climate-model simulation. Thus, it is possible to predict an increase of $3.6^{\circ} \mathrm{C}$ in the average annual air temperature and an increase of $231 \mathrm{~mm}$ in annual accumulated rainfall (equivalent to approximately $17 \%$ of the climatological normal) for the interval 2071-2099. Moreover, in relation to seasonal distribution, there is a higher monthly average temperature increase in the spring $\left(4.1^{\circ} \mathrm{C}\right)$ and
\end{abstract}


lower in the summer $\left(3.4^{\circ} \mathrm{C}\right)$ and a higher average daily increase in summer rainfall $(1.1 \mathrm{~mm})$ and smaller increase in spring $(0.3 \mathrm{~mm})$. There is also an increase of approximately 5 days in the daily number of days with greater than $1 \mathrm{~mm}$ precipitation throughout the year. The analysis of the water balance showed deficits in the months of August and September and found a disparity between the input and output of water entering the territory through precipitation, evapotranspiration, and water consumption, suggesting the need to adapt to new social and environmental scenarios.

Keywords: climate simulation, regional atmospheric model, water regional budget.

\section{INTRODUÇÃO}

Desde a década de 1980 evidências científicas sobre a possibilidade de mudança do clima em nível mundial vêm despertando interesses crescentes no público e na comunidade científica em geral (Marengo, 2008).

Em 1988, a Organização Meteorológica Mundial (OMM) e o Programa das Nações Unidas para o Meio Ambiente (PNUMA) estabeleceram o Intergovernmental Panel on Climate Change (IPCC), criado para fornecer informações técnicas e científicas sobre as mudanças climáticas. Em seu $5^{\circ}$ Relatório o IPCC apresentou evidências do agravamento das mudanças climáticas em relação aos extremos climáticos, sendo maiores na região tropical dos países menos desenvolvidos (IPCC, 2013).

Todos estes impactos no clima ocorrem devido ao aumento significativo da temperatura do ar, que tem ocorrido décadas após décadas. Segundo Marengo (2008) é possível observar um aumento de $1^{\circ} \mathrm{C}$ na América Central e na América do Sul em um século, em comparação a um valor médio mundial de $+0,74^{\circ} \mathrm{C} /$ por século (Marengo, 2008).

Projeções indicam uma mudança considerável no clima do Brasil neste século o que poderá se refletir em sua economia que é fortemente dependente das exportações de commodities agrícolas (IPEA, 2011), bem como na matriz energética brasileira dominada por fontes renováveis. E, ainda, o Brasil convive com a pobreza e a desigualdade social significativas (Confalonieri, 2003), que são problemas intensificados durante extremos climáticos.

Contudo, para o estudo de uma região específica, podem ocorrer mudanças significativas para os dois lados dos extremos, decorrentes destas variações climáticas e, por isso, são necessárias análises aprofundadas, através da comparação entre dados do passado e futuro para as condições locais. Casos pontuais, tais como as frequentes inundações na cidade de São Paulo no verão, os deslizamentos de terra no estado do Rio de Janeiro no verão de 2011, as epidemias de dengue em todo o país, sucessão de eventos de secas intensas e inundações na Amazônia e Nordeste e a estiagem profunda na região Sudeste, revelam como o Brasil é despreparado para as questões relativas às mudanças climáticas (Marengo et al., 2011).

Sobre esta problemática, inferências e prognósticos sobre o futuro são sempre desejados por autoridades e tomadores de decisão. Somente simulações climáticas podem fornecer algum tipo de projeção dos elementos do clima futuro, pois baseiam-se em modelos matemáticos que descrevem os movimentos das massas de ar e suas interações com os fatores climáticos.

Apesar disto, estes modelos apresentam algumas fontes de incertezas, sendo que para a atual geração de modelos usados pelo (IPCC, 2013), estas podem ser descritas como: Incertezas nas emissões futuras dos Gases do Efeito Estufa (GEEs) e aerossóis e da ocorrência de atividades vulcânicas e/ou ciclos solares; - Incertezas na inclusão dos efeitos no aumento da concentração de $\mathrm{CO}_{2}$ atmosférico nas plantas; - Incerteza na sensibilidade do clima global e nos padrões regionais das projeções de clima futuro simulados pelos modelos. 
Para melhorar a resolução e previsão dos cenários futuros, utiliza-se a redução da resolução espacial, através do uso de modelo de mesoescala (técnica do "downscaling"). Esse modelo foi instalado no CPTEC em 1996 com a finalidade de complementar a Previsão Numérica de Tempo que vem sendo realizada operacionalmente desde o início de 1995, acoplado com o modelo de circulação geral atmosférica HadCM3 (Vieira Júnior et al., 2009).

A região do Vale do Paraíba é uma região sócio-econômica que abrange parte do leste do estado de São Paulo, oeste do estado do Rio de Janeiro e sul de Minas Gerais, e que se destaca por concentrar uma parcela considerável do Produto Interno Bruto (PIB) do Brasil. Esta região tem passado por diversos tipos de catástrofes. Ayres (2010) realizou um extenso levantamento da ocorrência de desastres naturais, no período de 1990 a 2008, sendo que o tipo de evento de desastre natural de maior ocorrência foi de inundação (54\%), seguida de tempestades severas (26\%), deslizamentos de massa (10\%) e, por fim, as inundações acompanhadas de deslizamento de massa (10\%).

A precipitação é o elemento deflagrador destes desastres. A distribuição mensal de chuva nessa região tem sido discutida por vários autores (Fisch, 1999; Nunes e Calbete, 2000; Silva, 2011; Costa et al., 2012; Moraes, 2014), que mostraram a ocorrência de um período chuvoso com concentração de $75 \%$ da precipitação nos meses de outubro a março com chuvas mensais superiores a $150 \mathrm{~mm} / \mathrm{mês}$. O período de estiagem (junho a agosto), contribui com $7 \%$ da precipitação anual, com chuvas mensais inferiores a $50 \mathrm{~mm} / \mathrm{mês}$. O total anual é de 1.357 mm/ano (Horikoshi e Fisch, 2007). Vilaron e Fisch (2013) estudaram o mecanismo atmosférico que inicia a estação chuvosa na região, associando-o com a passagem de uma frente fria entre meados de setembro e início de outubro, para deflagrar as chuvas convectivas.

Sendo assim, o presente trabalho teve como objetivo analisar as variações dos elementos climáticos de temperatura e precipitação (nas escalas de tempo mensal, sazonal e anual) que ocorreram entre o passado (representado pelo intervalo de tempo entre os anos de 1961 a 1989) e o futuro, simuladas por um modelo de Circulação Geral da Atmosfera com o "downscaling" em escala regional, nos intervalos de tempo de 2011 a 2040, de 2041 a 2070 e de 2071 a 2099 trazendo subsídios para o conhecimento do clima e de planejamento da Região Metropolitana do Vale do Paraíba.

\section{MATERIAIS E MÉTODO}

Taubaté situa-se a $23^{\circ} 01^{\prime}$ de latitude sul e $45^{\circ} 33^{\prime}$ de longitude oeste, na mesorregião do Vale do Paraíba, distante $123 \mathrm{~km}$ da capital paulista, $280 \mathrm{~km}$ da cidade do Rio de Janeiro; situa-se entre as serras do Mar e da Mantiqueira e é cortada pela Via Dutra. Seu território abrange pouco mais de $625 \mathrm{~km}^{2}$ e abriga uma população estimada em cerca de 300 mil habitantes (IBGE, 2010).

O local de estudo correspondeu a uma área de $20 \mathrm{~km}$ no entorno do posto meteorológico da Universidade de Taubaté (Figura 1), localizada no Departamento de Ciências Agrárias.

O posto meteorológico possui uma EMA (Estação Meteorológica Automática) mantida através de uma cooperação com o CPTEC/INPE e uma EMC (Estação Meteorológica Convencional) mantida através de uma cooperação com o INMET (Figura 2).

A região pode ser caracterizada pelo clima tropical, com temperatura média anual é de $24^{\circ} \mathrm{C}$, inverno seco e verões chuvosos, respectivamente $7 \%$ e $44 \%$ da precipitação anual. Apresenta índice pluviométrico médio de $112,9 \mathrm{~mm}$ de precipitação mensal, que implica em cerca de $1350 \mathrm{~mm}$ de total pluviométrico anual. Possui ainda ventos predominantes de sulleste para o norte-oeste e umidade relativa do ar na média de $60 \%$ às doze horas (Fisch, 1999). 


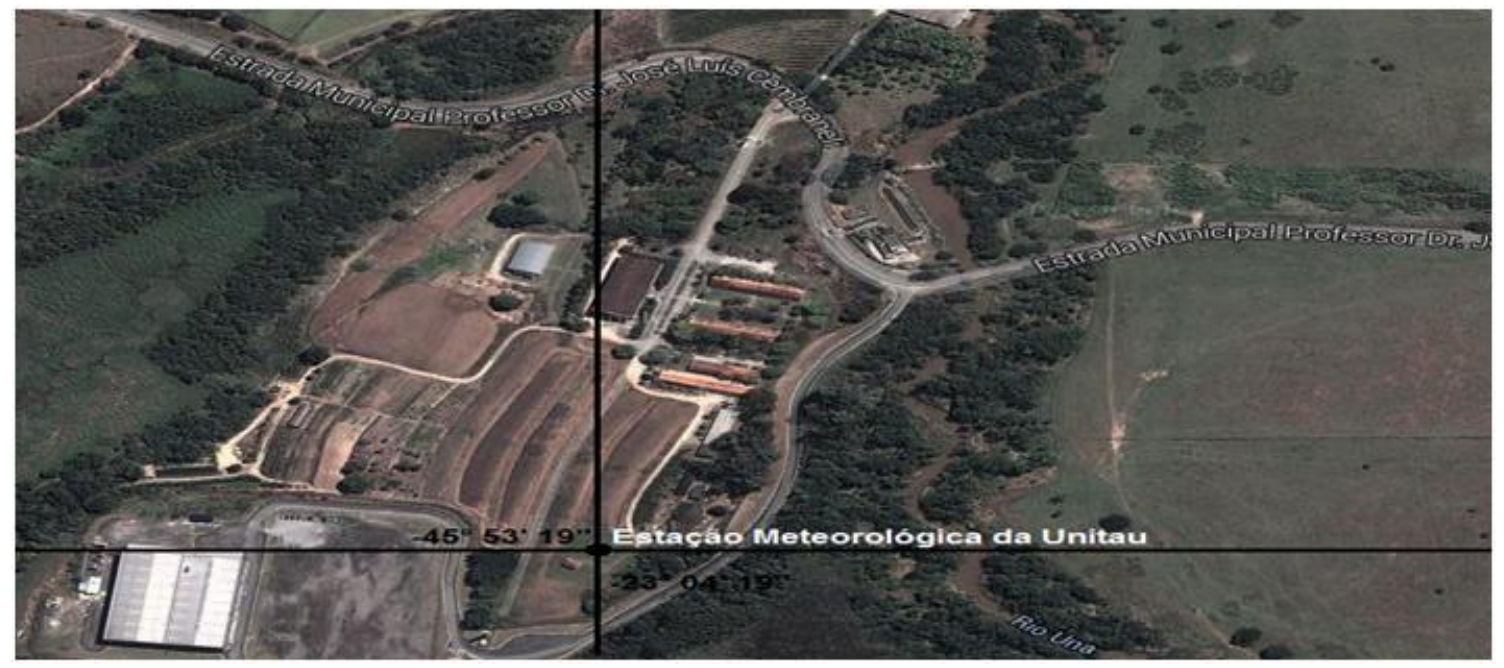

Figura 1. Localização da estação meteorológica da UNITAU e suas coordenadas geográficas. Fonte: Google Maps, 2014.
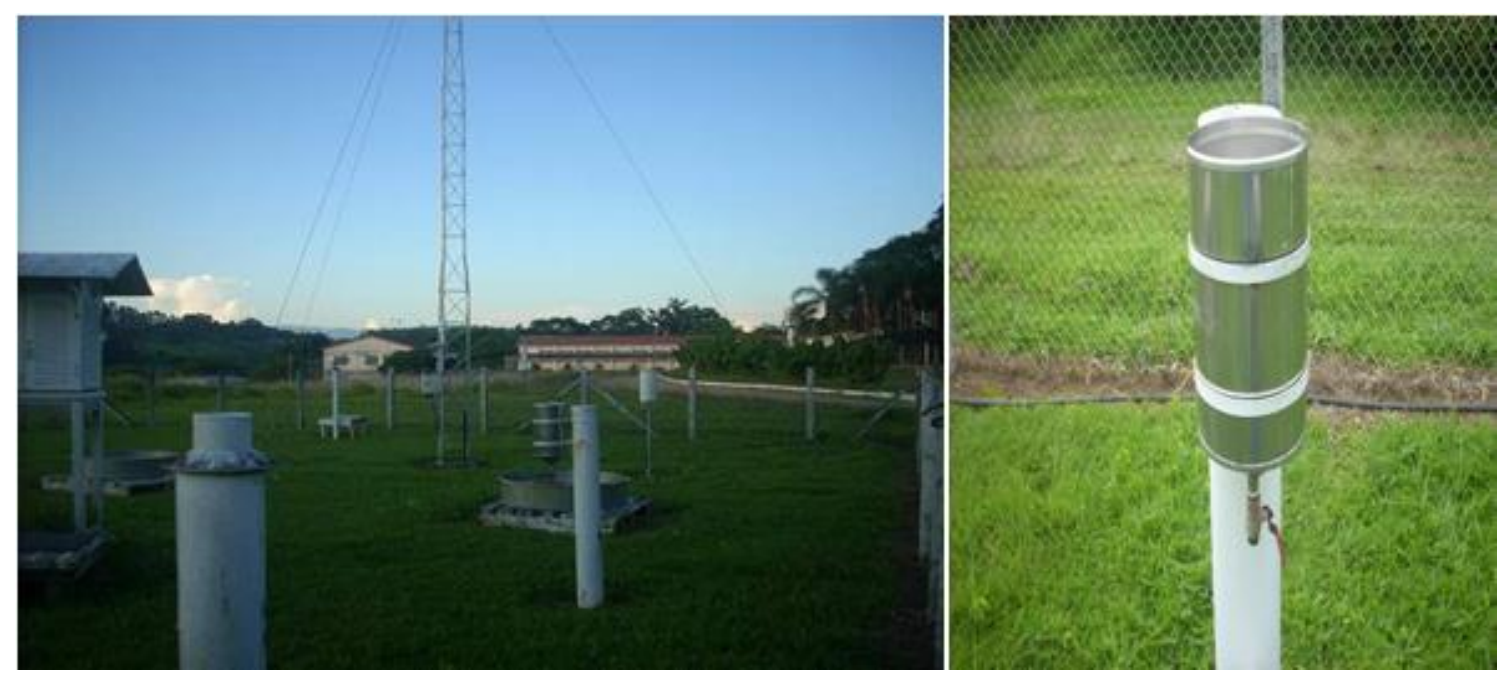

Figura 2. Estação meteorológica da Universidade de Taubaté (à esquerda). Pluviômetro (à direita).

Fonte: Silva, 2011.

Os dados de precipitação e temperatura observados obtidos por meio da estação meteorológica de Taubaté, do período de 1960 a 1977, foram extraídos do banco de dados INMET, mediante a um cadastro no site, e exportados para o Microsoft Excel, para a manipulação dos dados. Estes dados foram analisados e confrontados com os dados de simulação futura, calculado e compilado, através de modelos matemáticos, pelo supercomputador do INPE e extraído através do software Open Grads, através de linguagem de programação, para a devida correção. Neste trabalho foram utilizadas previsões de simulação climática com resolução de 20 X $20 \mathrm{~km}$

Todas as análises para os dados de simulação do futuro (escalas de tempo mensal, sazonal e anual) foram comparadas com os dados do passado (ou "baseline"), que foi definido como valor climatológico entre 1961-1990, tanto para os valores de precipitação (média, máxima e acumulada) como para os de temperatura (média, máxima e mínima extremas). Como o ano final da ultima série temporal é 2099, foi feito um ajuste para os anos finais das outras séries temporais, ou seja, para a série 2011-2040, foi feito uma média aritmética entre 2039 e 2040, para a série 2041-2070, um média entre 2069 e 2070, assim também para o passado, com 
uma média entre 1989 e 1990. Este procedimento foi realizado para garantir que todos os conjuntos de dados tivessem o mesmo número de anos de dados nas análises.

\section{1. Índice de Seca (Método dos QUANTIS)}

Segundo Xavier et al. (2002), o método dos quantis baseia-se em uma longa série de registros pluviométricos, onde a precipitação total $\mathbf{X}$ de um ano da localidade, ao longo de anos ininterruptos é uma variável aleatória contínua. Uma interpretação simples para o quantil $\mathrm{Q}_{\mathrm{p}}$ é a seguinte, supondo que $\mathbf{p}$ se expressa em potenciais: tem-se que em $\mathbf{p} \%$ dos anos a quantidade de precipitação $\mathbf{X}$ não deve ultrapassar o valor do quantil $Q_{p}$, enquanto para (100 - p)\% dos anos esse valor será excedido. Os quantis reportam-se as ordens $\mathrm{Q}_{0,05}$, $\mathrm{Q}_{0,25}, \mathrm{Q}_{0,50}, \mathrm{Q}_{0,75}, \mathrm{Q}_{0,95}(5 \% ; 25 \% ; 50 \%, 75 \%$ e $95 \%)$, que variaram conforme uma escala adaptada (Tabela 1), segundo Gois et al. (2007).

Tabela 1. Categoria dos Quantis e Classificação.

\begin{tabular}{lll}
\hline Quantis & \multicolumn{1}{c}{ Categoria } & \multicolumn{1}{c}{ Classificação } \\
\hline Q $(0,05)$ & Abaixo de 5\% & Seca Extrema (SE) \\
Q $(0,25)$ & Igual ou inferior a 25\% & Seca Severa (SS) \\
Q $(0,50)$ & Média de 50\% & Próximo da normal (PN) \\
Q $(0,75)$ & Igual ou superior a 75\% & Úmido (U) \\
Q $(0,95)$ & Superior a 95\% & Muito Úmido (UM) \\
\hline
\end{tabular}

Fonte: Gois et al. (2007).

Este trabalho reservou algumas ordens quantílicas chave, a saber, $\mathrm{Q}_{0,05}, \mathrm{Q}_{0,15}, \mathrm{Q}_{0,35}, \mathrm{Q}_{0,65}$ e $\mathrm{Q}_{0,85}, \mathrm{Q}_{0,95}$ para estabelecer as seguintes classes com relação aos valores mensais observados (Xi) de precipitação:

Adaptando o método para a região estudada (Tabela 2) têm-se as probabilidades ou frequências esperadas para os eventos: "extremamente seco", "muito seco", "seco", "normal", "chuvoso", "muito chuvoso" e "extremamente chuvoso", respectivamente, durante uma sequência de anos para os quais seja possível a manutenção das mesmas características para as chuvas, comparativamente ao período utilizado para o cálculo dos quantis.

Tabela 2. Categoria dos quantis.

\begin{tabular}{lll}
\hline \multicolumn{1}{c}{ Quantis } & \multicolumn{1}{c}{ Categoria } & \multicolumn{1}{c}{ Classificação } \\
\hline $\mathrm{P}<\mathrm{Q}(0,05)$ & Abaixo de 5\% & Extremamente seco (ES) \\
$\mathrm{Q}(0,05)<\mathrm{P}<\mathrm{Q}(0,15)$ & Entre 5\% e 15\% & Muito Seco (MS) \\
$\mathrm{Q}(0,15)<\mathrm{P}<\mathrm{Q}(0,35)$ & Entre $15 \%$ e 35\% & Seco $(\mathrm{S})$ \\
$\mathrm{Q}(0,35)<\mathrm{P}<\mathrm{Q}(0,65)$ & Entre 35\% e 65\% & Normal (N) \\
$\mathrm{Q}(0,65)<\mathrm{P}<\mathrm{Q}(0,85)$ & Entre 65\% e 85\% & Chuvoso (C) \\
$\mathrm{Q}(0,85)<\mathrm{P}<\mathrm{Q}(0,95)$ & Entre $85 \%$ e $95 \%$ & Muito Chuvoso (MC) \\
$\mathrm{Q}(0,95)<\mathrm{P}$ & Superior a 95\% & Extremamente Chuvoso (EC) \\
\hline
\end{tabular}

Fonte: Breiman (1973). 


\subsection{Dias ininterruptos de precipitação}

Utilizou-se a frequência absoluta para representar os meses de ocorrência dos eventos de precipitação categorizando em número de dias seguidos de chuvas. Para cada caso selecionado, foram calculadas as precipitações médias acumuladas, total de precipitação anual, precipitação máxima anual, quantidade de dias máximos ininterruptos e média de precipitação dos dias seguidos de chuva, dando ênfase na comparação entre o passado ("baseline") e as médias das simulações futuras.

\subsection{Classificação de chuva quanto a intensidade diária}

Também para a classificação de intensidade de chuva, Tabela 3, foram utilizados dados de precipitação diária, separando cada precipitação em uma escala, quanto a sua intensidade.

Tabela 3. Classificação quanto a intensidade de precipitação.

\begin{tabular}{ll}
\hline Intensidade & Classificação \\
\hline $\mathrm{P}<1 \mathrm{~mm}$ & Ausência \\
$1 \mathrm{~mm}<\mathrm{P}<10 \mathrm{~mm}$ & Fraca \\
$10 \mathrm{~mm}<\mathrm{P}<30 \mathrm{~mm}$ & Moderada \\
$30 \mathrm{~mm}<\mathrm{P}<50 \mathrm{~mm}$ & Forte \\
$\mathrm{P}>50 \mathrm{~mm}$ & Intensa \\
\hline
\end{tabular}

\section{RESULTADOS E DISCUSSÃO}

\subsection{Comparação entre dados de observação e de simulação passada (baseline)}

Inicialmente procedeu-se uma avaliação da habilidade do modelo em representar o clima do passado (1961-1990 - denominado de baseline). Obteve-se uma diferença, em geral, um viés negativo (na média de $-1,6 \mathrm{~mm} / \mathrm{dia}$, mas com valores variando entre $-3,8 \mathrm{~mm} / \mathrm{dia}$ (outubro) a $+0,2 \mathrm{~mm} /$ dia (março), resultados apresentados na Tabela 4.

Tabela 4. Diferenciação de precipitação.

\begin{tabular}{lc}
\hline \multicolumn{1}{c}{ Mês } & $\begin{array}{c}\text { Diferenciação observação } \\
\text { simulação }\end{array}$ \\
\hline Janeiro & $-0,5 \mathrm{~mm}$ \\
Fevereiro & $-0,8 \mathrm{~mm}$ \\
Março & $+0,2 \mathrm{~mm}$ \\
Abril & $-2,0 \mathrm{~mm}$ \\
Maio & $-1,2 \mathrm{~mm}$ \\
Junho & $-1,2 \mathrm{~mm}$ \\
Julho & $-1,0 \mathrm{~mm}$ \\
Agosto & $-1,6 \mathrm{~mm}$ \\
Setembro & $-3,2 \mathrm{~mm}$ \\
Outubro & $-3,8 \mathrm{~mm}$ \\
Novembro & $-3,4 \mathrm{~mm}$ \\
Dezembro & $-0,7 \mathrm{~mm}$ \\
\hline Média & $\mathbf{- 1 , 6 ~ m m}$ \\
\hline
\end{tabular}


Com relação aos valores de temperatura do ar, houve uma diferença entre as observações e as simulações de clima passado de aproximadamente $+1,9^{\circ} \mathrm{C}$, ocorrendo também variações entre os meses (Tabela 5 e Figura 4). O modelo sempre apresenta temperaturas mais baixas do que as observações.

Tabela 5. Diferenciação de temperatura.

\begin{tabular}{lc}
\hline Mês & $\begin{array}{c}\text { Diferenciação } \\
\text { observação simulação }\end{array}$ \\
\hline Janeiro & $+2,5^{\circ} \mathrm{C}$ \\
Fevereiro & $+3,2^{\circ} \mathrm{C}$ \\
Março & $+3,4^{\circ} \mathrm{C}$ \\
Abril & $+2,2^{\circ} \mathrm{C}$ \\
Maio & $+1,7^{\circ} \mathrm{C}$ \\
Junho & $+1,4^{\circ} \mathrm{C}$ \\
Julho & $+0,6^{\circ} \mathrm{C}$ \\
Agosto & $+0,8^{\circ} \mathrm{C}$ \\
Setembro & $+1,0^{\circ} \mathrm{C}$ \\
Outubro & $+0,8^{\circ} \mathrm{C}$ \\
Novembro & $+1,9^{\circ} \mathrm{C}$ \\
Dezembro & $+2,4^{\circ} \mathrm{C}$ \\
\hline Média & $+\mathbf{1 , 9} 9^{\circ} \mathrm{C}$
\end{tabular}

Com estas diferenças obtidas entre os dados de observação e de simulação do passado, foram corrigidos os dados de simulação futura e analisados segundo as escalas de tempo mensal, sazonal e anual. Tais dados foram estudados e tratados afim de que se tivesse uma previsão de cenário futuro para as próximas séries temporais de intervalo de tempo (2011-2040, 2041-2070, 2071-2099).

\subsection{Simulação da precipitação}

A partir dos dados de simulação climática da precipitação diária, foram obtidos os valores médios mensais e estes foram analisados por série temporal mês a mês. Cada mês analisado foi compilado e extraindo-se um valor médio de precipitação, como observado na Figura 4. A partir destes resultados, foi possível sintetizá-los na Tabela 6.

Como observado na Tabela 6, houve um aumento no valor médio referente a cada intervalo de tempo. Na simulação do passado ou "baseline" (1961-1990), tinha-se uma média diária de 3,8 mm de chuva. Na primeira série temporal simulada (2011-2040) obteve-se um aumento para $4,3 \mathrm{~mm}$, com o sucessivo aumento para 4,4 $\mathrm{mm}$ nas séries seguintes (2041-2070 e 2071-2099). Com relação às anomalias (Tabela 6), verifica-se que, nos meses de julho e setembro, a anomalia média de precipitação para o intervalo de tempo de 20712099 foi negativa. Entretanto, o mês de novembro foi o que apresentou o maior acréscimo para este mesmo intervalo de tempo. Este comportamento pode estar associado a uma pequena variação do início da estação chuvosa na região, com sua antecipação para o final do século XXI. Os totais anuais sempre apresentam uma anomalia positiva, indicando que a região terá uma maior quantidade de água pelas chuvas. 
Tabela 6. Precipitação e anomalia diária média (em mm) por série temporal mensal simulado.

\begin{tabular}{|c|c|c|c|c|c|c|c|}
\hline \multicolumn{5}{|c|}{ Precipitação média diária } & \multicolumn{3}{|c|}{ Anomalias } \\
\hline Mês & $1961-1990$ & $2011-2040$ & $2041-2070$ & 2071-2099 & $2011-2040$ & 2041-2070 & 2071-2099 \\
\hline JAN & 6,8 & 8,8 & 8,9 & 8,3 & 2,0 & 2,1 & 1,5 \\
\hline FEV & 7,0 & 7,2 & 7,3 & 7,4 & 0,2 & 0,3 & 0,4 \\
\hline MAR & 6,2 & 7,1 & 6,7 & 6,5 & 0,9 & 0,5 & 0,3 \\
\hline $\mathrm{ABR}$ & 1,8 & 2,0 & 2,3 & 2,5 & 0,2 & 0,5 & 0,7 \\
\hline MAI & 1,1 & 1,4 & 2,0 & 1,9 & 0,3 & 0,9 & 0,8 \\
\hline JUN & 0,6 & 1,5 & 1,6 & 1,9 & 0,9 & 1,0 & 1,3 \\
\hline JUL & 1,0 & 1,0 & 1,4 & 0,9 & 0,0 & 0,4 & $-0,1$ \\
\hline AGO & 1,0 & 1,4 & 1,5 & 1,2 & 0,4 & 0,5 & 0,2 \\
\hline SET & 2,1 & 1,7 & 1,1 & 1,9 & $-0,4$ & $-1,0$ & $-0,2$ \\
\hline OUT & 4,2 & 4,5 & 4,3 & 4,7 & 0,3 & 0,1 & 0,5 \\
\hline NOV & 5,6 & 5,9 & 6,7 & 7,4 & 0,3 & 1,1 & 1,8 \\
\hline DEZ & 8,2 & 8,9 & 9,3 & 8,7 & 0,7 & 1,1 & 0,5 \\
\hline Média & 3,8 & 4,3 & 4,4 & 4,4 & 0,5 & 0,6 & 0,6 \\
\hline
\end{tabular}

As Figuras 3 e 4 mostram dois meses com características contrastantes (janeiro e julho), onde nota-se que o mês de janeiro teve um aumento de precipitação, média de $1,9 \mathrm{~mm}$, e julho, na média, praticamente não houve variação. Ressalta-se, porém, que a precipitação média do mês de julho é muito baixa, da ordem de 30-40 mm/mês, segundo Fisch (1995).

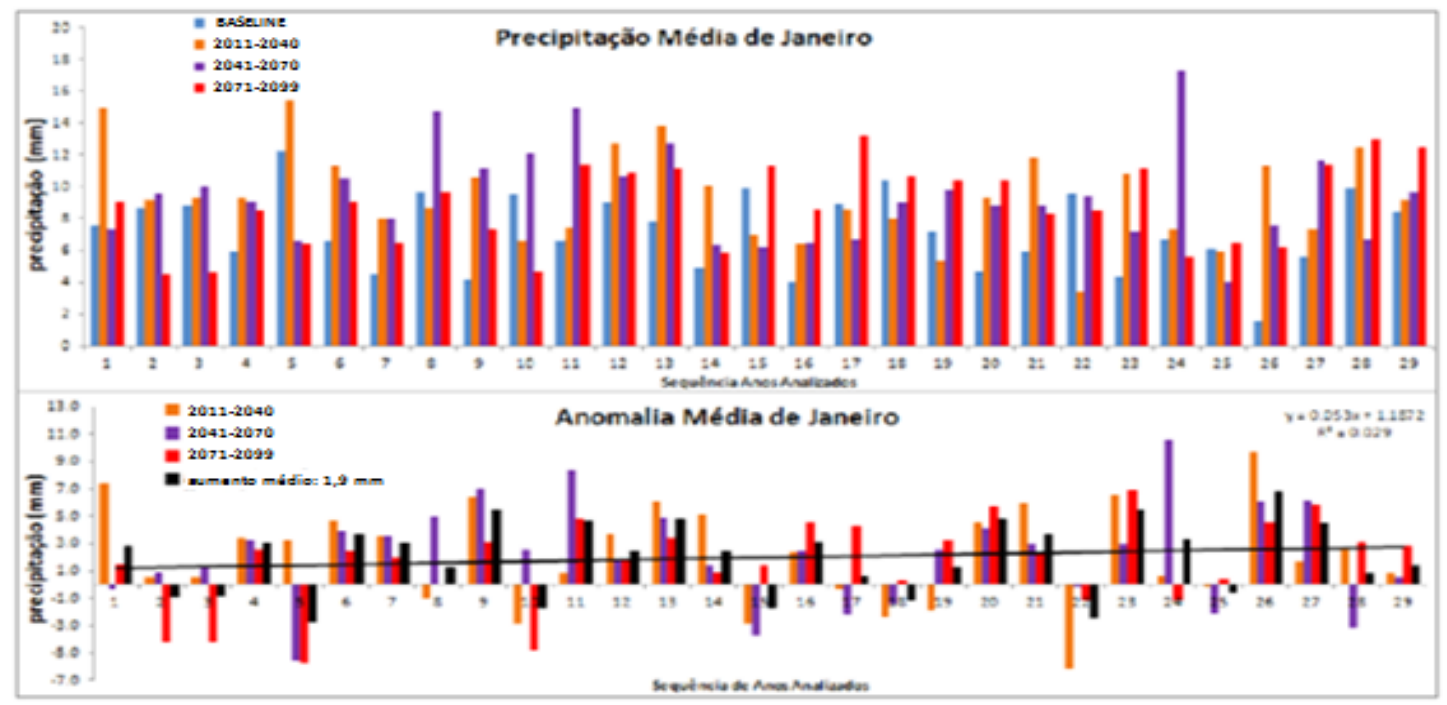

Figura 3. Precipitação e anomalia média de janeiro por série temporal. 


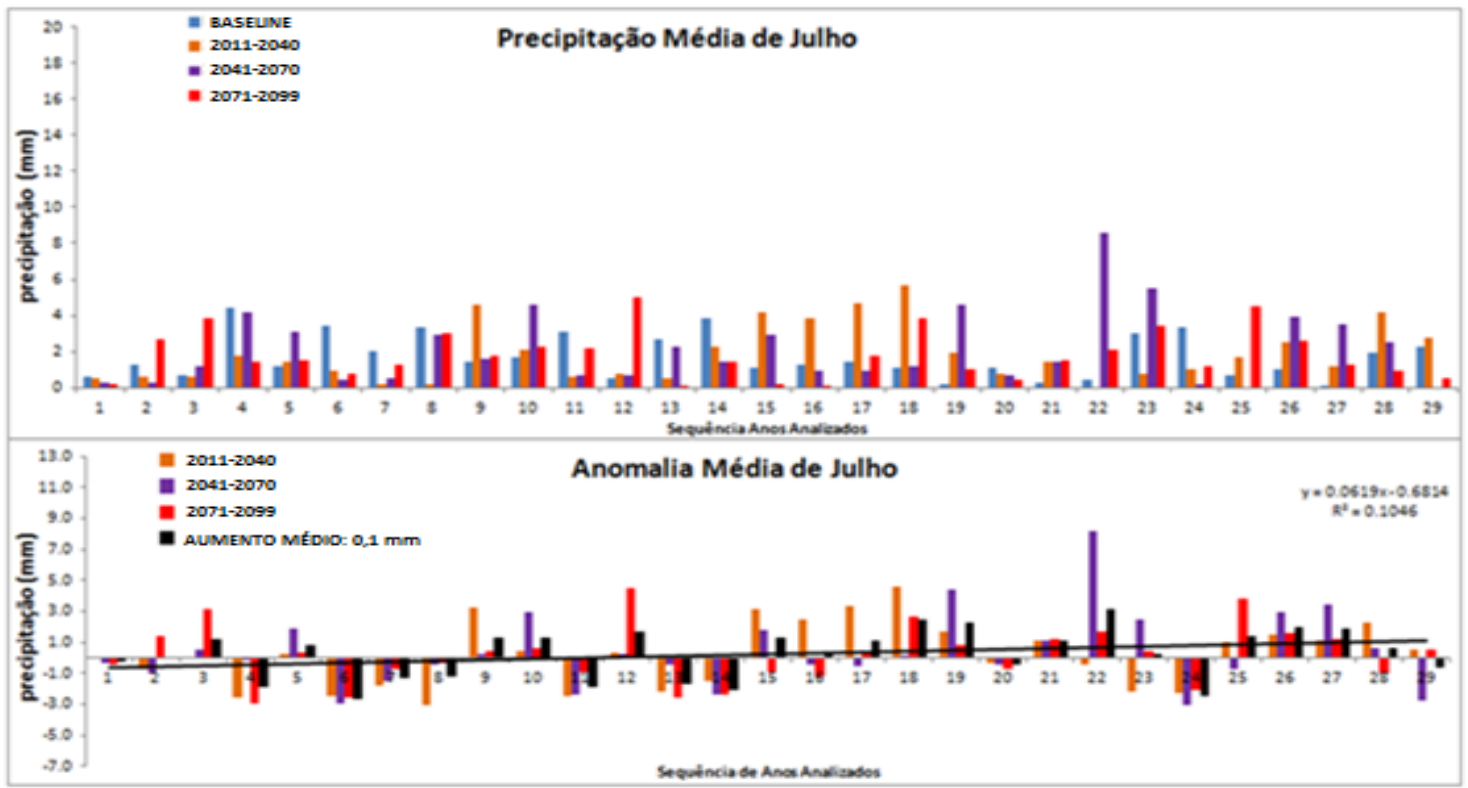

Figura 4. Precipitação e anomalia média de julho por série temporal.

A distribuição mensal do regime pluviométrico dos intervalos de tempo utilizados, bem como suas anomalias, estão descritas, respectivamente, nas Figuras 5 e 6.

Levando-se em conta as incertezas destas simulações e comparando os dados passados com os dados do intervalo de 2071-2099, ter-se-á, para a escala de tempo anual, um aumento na precipitação acumulada anual, de $231 \mathrm{~mm}$ que implica num total acumulado de $1599 \mathrm{~mm}$ anuais, quantidade superior a $113 \mathrm{~mm}$ em relação ao analisado em Horikoshi e Fisch (2007). No que diz respeito às tendências de precipitação, nota-se uma queda em relação ao aumento linear, observado pela linha de tendência dos dados (Figura 7).

Os maiores aumentos de precipitação foram observados nos meses de novembro e janeiro, meses pertencentes ao verão, com valores médios de 1,8 e $1,5 \mathrm{~mm} / \mathrm{dia}$, respectivamente. Já para os meses de julho e setembro, observa-se uma redução de 0,2 e 0,1 $\mathrm{mm} / \mathrm{dia}$, respectivamente. Mas novamente ressalta-se de que estes são meses com pouca chuva, não tem um impacto significativo no ciclo hidrológico.

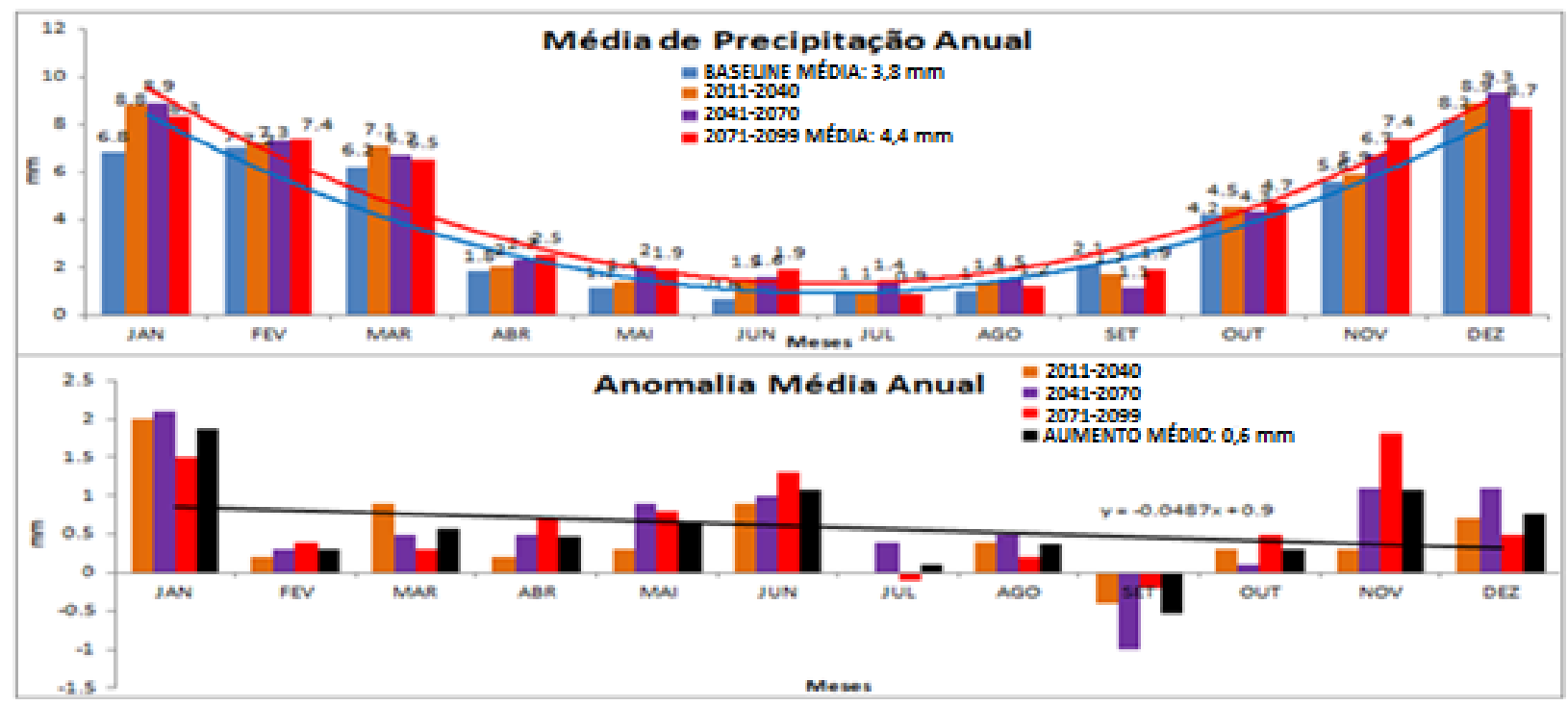

Figura 5. Precipitação e anomalia média anual (mês a mês) por série temporal. 


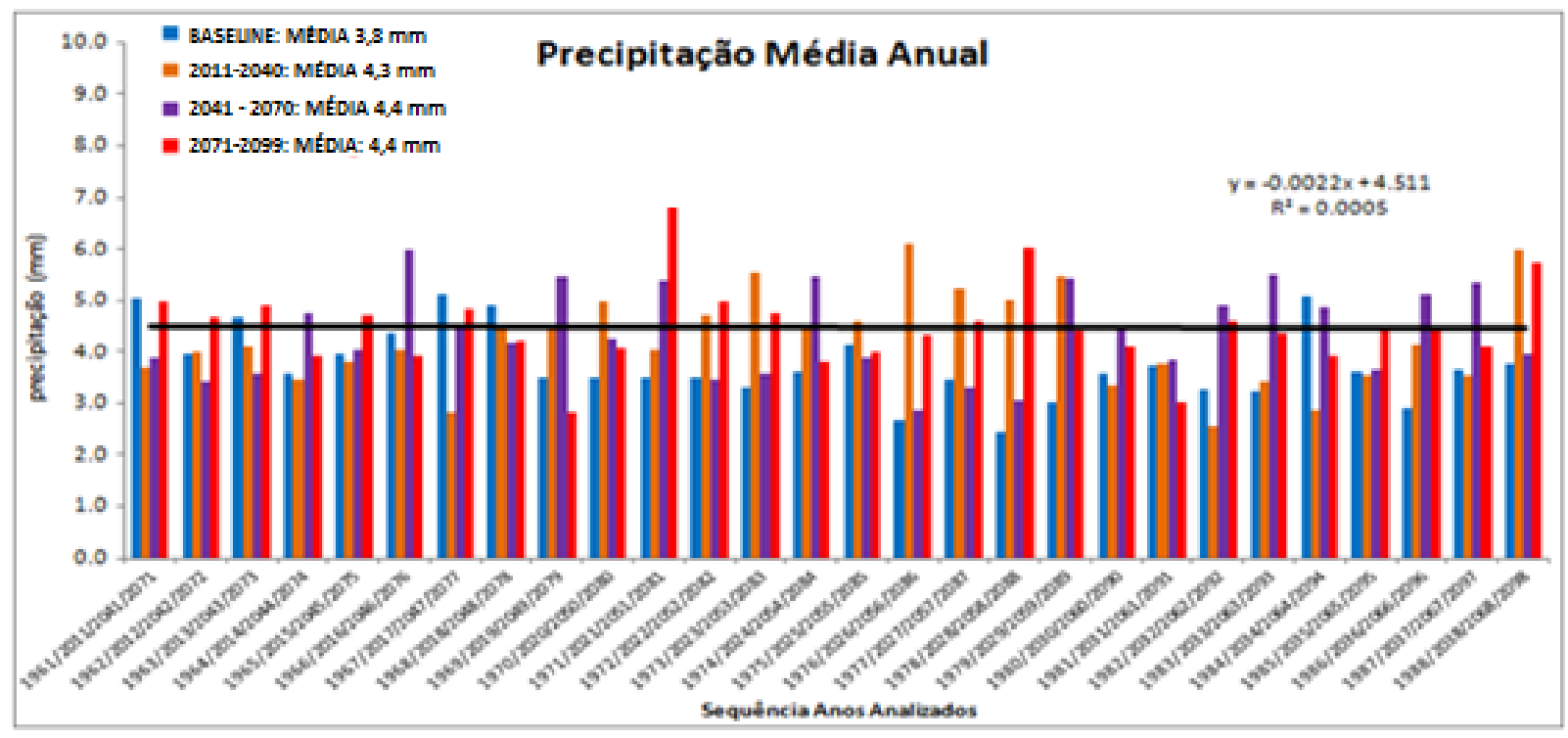

Figura 6. Tendência de precipitação média anual.

Observa-se, pelas análises da Tabela 7, que na precipitação sazonal houve um maior aumento de chuva na primavera (setembro, outubro e novembro) em relação aos dados de baseline e na última série temporal, ao passo que o menor aumento sazonal ocorreu no inverno (junho, julho e agosto).

Tabela 7. Precipitação média e anomalia sazonal por série temporal.

\begin{tabular}{lccccccc}
\hline \multicolumn{3}{c}{ Precipitação Média } \\
\hline Estação & $1960-1990$ & $2010-2040$ & $2041-2070$ & $2071-2099$ & $2010-2040$ & $2041-2070$ & $2071-2099$ \\
Outono & 3,0 & 3,5 & 3,5 & 3,6 & 0,5 & 0,5 & 0,6 \\
Inverno & 0,7 & 1,2 & 1,3 & 1,0 & 0,5 & 0,6 & 0,3 \\
Primavera & 3,6 & 3,7 & 3,8 & 4,7 & 0,1 & 0,2 & 1,1 \\
Verão & 7,3 & 8,1 & 8,6 & 8,3 & 0,8 & 1,3 & 1,0 \\
\hline
\end{tabular}

\subsection{Simulaçâo datemperatura do ar}

A temperatura do ar também foi analisada mês a mês, extraindo-se um valor médio para cada série temporal, além do valor de anomalia. A Figura 7 apresenta valores médios mensais e de anomalia e a Figura 8 apresenta a tendência linear de temperatura do ar anual.

Para a escala de tempo anual, ter-se-á um aumento de temperatura do ar de $3,6^{\circ} \mathrm{C}$, confirmando a mesma faixa de aumento de temperatura de Horikoshi e Fisch (2007). Os resultados mostram uma tendência de aumento de temperatura para os próximos anos, indicada pela linha de tendência (Figura 9). Os resultados das médias de temperatura e anomalias (Tabela 8) mostram uma temperatura ascendente com maior intensidade no mês de outubro e menor intensidade no mês de março, com todos os meses aumentando de um valor aproximado de $3,0^{\circ} \mathrm{C}$ entre o intervalo de tempo do passado ("baseline") e do futuro (2071-2099). 


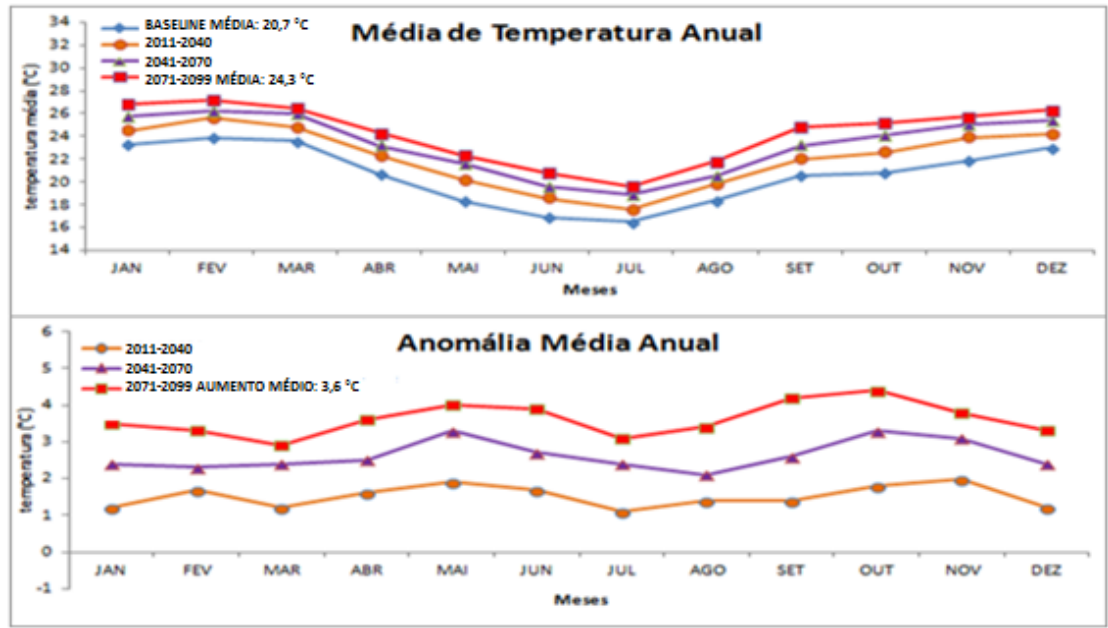

Figura 7. Temperatura e anomalia média anual (mês a mês) por série temporal.

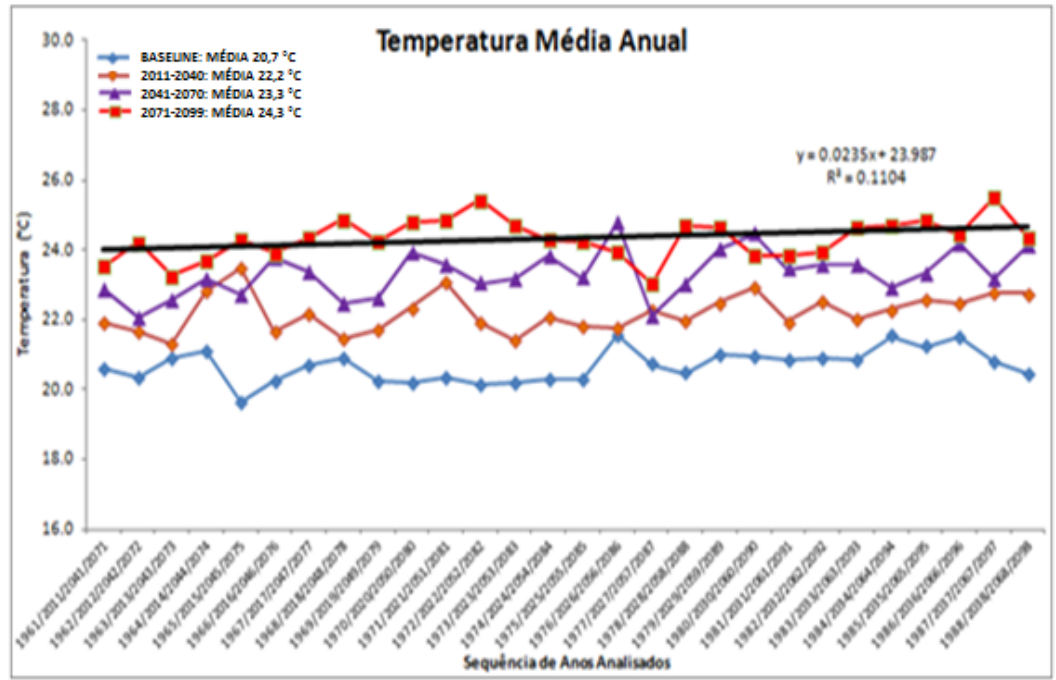

Figura 8. Tendência de temperatura do ar anual.

Tabela 8. Temperatura e anomalia média mensal por série temporal.

\begin{tabular}{|c|c|c|c|c|c|c|c|}
\hline \multicolumn{5}{|c|}{ Temperatura média mensal } & \multicolumn{3}{|c|}{ Anomalias } \\
\hline Mês & $1961-1990$ & $2011-2040$ & $2041-2070$ & 2071-2099 & $2011-2040$ & $2041-2070$ & 2071-2099 \\
\hline Janeiro & 23,3 & 24,5 & 25,7 & 26,8 & 1,2 & 2,4 & 3,5 \\
\hline Fevereiro & 23,9 & 25,6 & 26,2 & 27,2 & 1,7 & 2,3 & 3,3 \\
\hline Março & 23,6 & 24,8 & 26,0 & 26,5 & 1,2 & 2,4 & 2,9 \\
\hline Abril & 20,7 & 22,3 & 23,2 & 24,3 & 1,6 & 2,5 & 3,6 \\
\hline Maio & 18,3 & 20,2 & 21,6 & 22,3 & 1,9 & 3,3 & 4,0 \\
\hline Junho & 16,9 & 18,6 & 19,6 & 20,8 & 1,7 & 2,7 & 3,9 \\
\hline Julho & 16,5 & 17,6 & 18,9 & 19,6 & 1,1 & 2,4 & 3,1 \\
\hline Agosto & 18,4 & 19,8 & 20,5 & 21,8 & 1,4 & 2,1 & 3,4 \\
\hline Setembro & 20,6 & 22,0 & 23,2 & 24,8 & 1,4 & 2,6 & 4,2 \\
\hline Outubro & 20,8 & 22,6 & 24,1 & 25,2 & 1,8 & 3,3 & 4,4 \\
\hline Novembro & 21,9 & 23,9 & 25,0 & 25,7 & 2,0 & 3,1 & 3,8 \\
\hline Dezembro & 23,0 & 24,2 & 25,4 & 26,3 & 1,2 & 2,4 & 3,3 \\
\hline Média & 20,7 & 22,2 & 23,3 & 24,3 & 1,5 & 2,6 & 3,6 \\
\hline
\end{tabular}

Rev. Ambient. Água vol. 11 (suplemento) Taubaté, 2016 
Observa-se, nas Figuras 9 e 10, um aumento médio de temperatura dentro do ciclo annual para os meses contrastantes de Janeiro e Julho, da ordem de $3^{\circ} \mathrm{C}$.

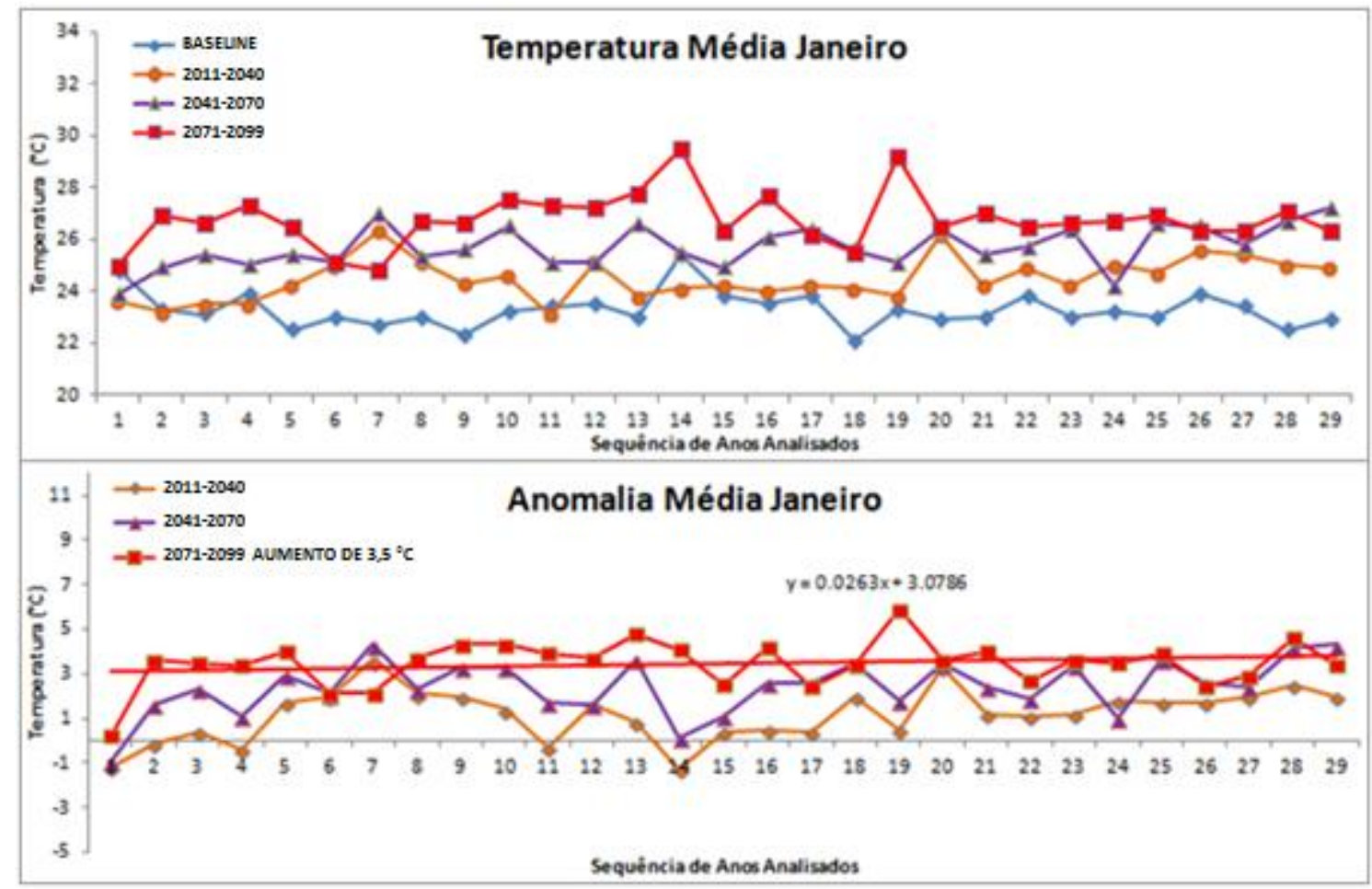

Figura 9. Temperatura e anomalia média para o mês de Janeiro.

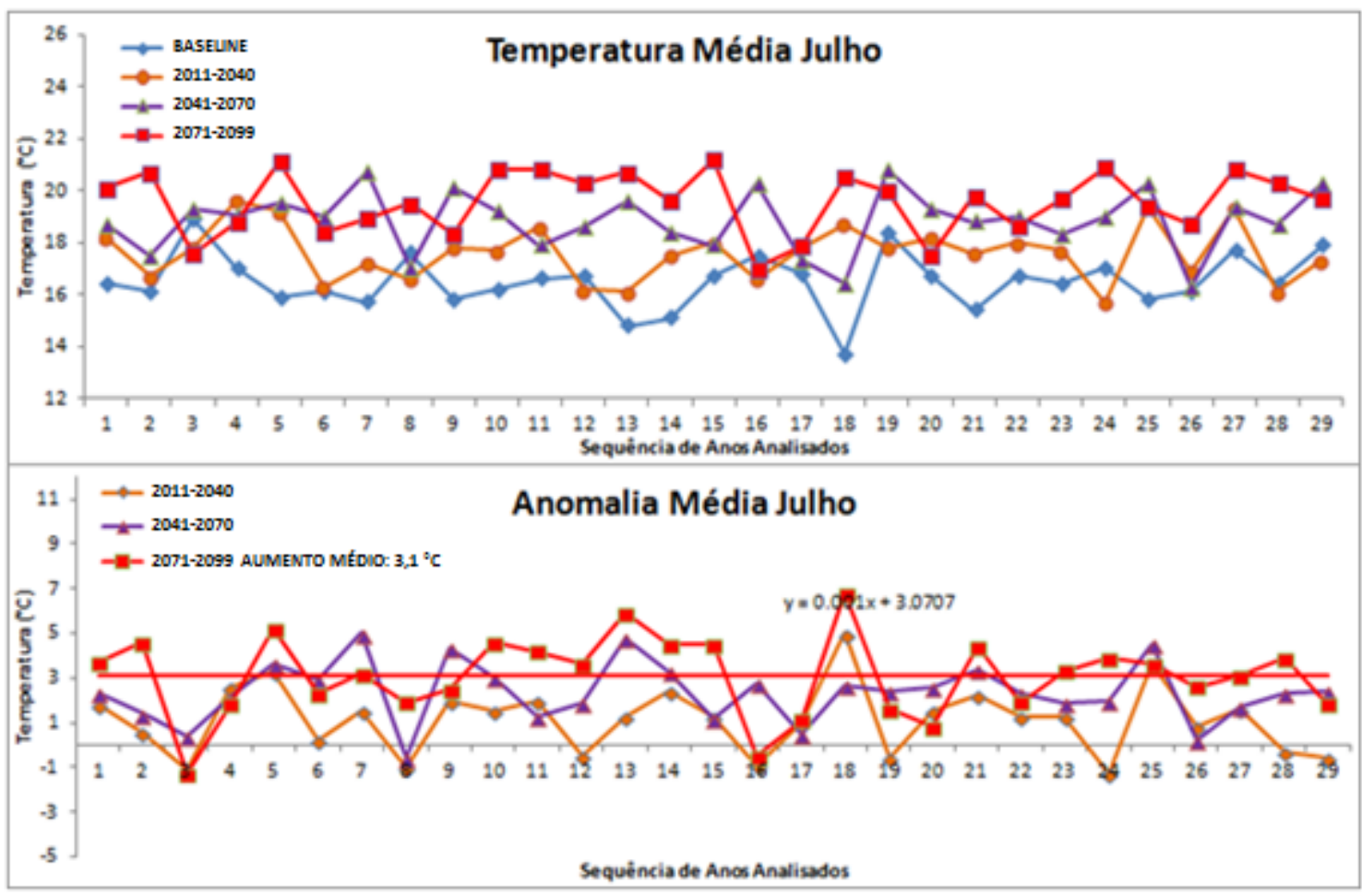

Figura 10. Temperatura e anomalia média para o mês de Julho. 
A Tabela 9 mostra que as temperaturas sazonais apresentam particularidades em cada estação, porém o maior aumento ocorre na primavera, ao passo que o menor aumento ocorre no verão (dezembro, janeiro e fevereiro).

Tabela 9. Temperatura média e anomalia sazonal por série temporal.

\begin{tabular}{|c|c|c|c|c|c|c|c|}
\hline \multicolumn{5}{|c|}{ Temperatura média } & \multicolumn{3}{|c|}{ Anomalia } \\
\hline séries & $1961-1990$ & $2011-2040$ & $2041-2070$ & 2071-2099 & 2011-2040 & $2041-2070$ & 2071-2099 \\
\hline Outono & 20,8 & 22,3 & 23,5 & 24,4 & 1,3 & 2,5 & 3,6 \\
\hline Inverno & 17,2 & 18,6 & 19,6 & 20,7 & 1,4 & 2,4 & 3,5 \\
\hline Primavera & 21,1 & 22,8 & 24,1 & 25,2 & 1,7 & 3,0 & 4,1 \\
\hline Verão & 23,4 & 24,7 & 25,8 & 26,8 & 1,6 & 2,7 & 3,4 \\
\hline
\end{tabular}

\subsection{Eventos extremos: temperaturas máximas e mínimas e precipitação máxima}

Foram analisados os valores extremos da precipitação e temperatura do ar, considerando-se os valores máximos de precipitação, (Tabela 10) e os valores máximos e mínimos (Tabela 11) de temperatura mensal, com suas respectivas anomalias.

Os resultados demonstraram que houve um aumento em relação aos valores de precipitações extremas (Tabela 10). O maior valor das precipitações máximas simuladas desloca-se no tempo entre a primavera (em outubro no intervalo de tempo baseline) para o verão (em dezembro no íntervalo de tempo futuro), indicando que as chuvas serão mais intensas e de origem convectivas. Da mesma forma, as menores chuvas intensas, antecipamse entre o inverno (em junho) para o final do outono (em maio), considerando-se os mesmos intervalos de tempo. Isto representa uma maior possibilidade de desastres naturais, tais como enchentes e/ou deslizamento de terra.

Nos valores extremos de temperatura máxima, observou-se que o mês de novembro apresentou o maior aumento de temperatura $\left(6,1^{\circ} \mathrm{C}\right)$. Os meses de julho e agosto se mostraram com o menor aumento das máximas $\left(3,4^{\circ} \mathrm{C}\right)$. Estes valores e suas respectivas anomalias por intervalo de tempo estão presentes na Tabela 11.

Tabela 10. Máximas de precipitação mensal por série temporal (mm/dia).

\begin{tabular}{lcccc}
\hline & $1961-1990$ & $2011-2040$ & $2041-2070$ & $2071-2099$ \\
\hline Janeiro & 54,5 & 76,7 & 65,4 & 75,6 \\
Fevereiro & 58,3 & 45,4 & 66,6 & 51,3 \\
Março & 48,5 & 53,1 & 58,1 & 48,2 \\
Abril & 49,8 & 47,3 & 56,7 & 52,5 \\
Maio & 35,5 & 58,1 & 47,4 & 37,5 \\
Junho & 32,4 & 53,6 & 61,3 & 47,4 \\
Julho & 54,3 & 43,5 & 56,3 & 44,5 \\
Agosto & 39,8 & 51,0 & 57,8 & 44,1 \\
Setembro & 60,6 & 62,6 & 63,8 & 68,5 \\
Outubro & 69,9 & 67,7 & 59,8 & 71,1 \\
Novembro & 58,9 & 62,2 & 67,2 & 56,5 \\
Dezembro & 66,8 & 63,8 & 69,7 & 79,5 \\
\hline Máximo & $\mathbf{6 9 , 9}$ & $\mathbf{7 6 , 7}$ & $\mathbf{6 9 , 7}$ & $\mathbf{7 9 , 5}$ \\
\hline Mínimo & $\mathbf{3 2 , 4}$ & $\mathbf{4 3 , 5}$ & $\mathbf{4 7 , 4}$ & $\mathbf{3 7 , 5}$ \\
\hline
\end{tabular}

Rev. Ambient. Água vol. 11 (suplemento) Taubaté, 2016 
Tabela 11. Valores Máximos de temperatura mensal e anomalias por intervalo de tempo.

\begin{tabular}{|c|c|c|c|c|c|c|c|}
\hline \multicolumn{5}{|c|}{ Temperaturas Máximas } & \multicolumn{3}{|c|}{ Anomalias } \\
\hline & $1961-1990$ & 2011-2040 & $2041-2070$ & 2071-2099 & 2011-2040 & $2041-2070$ & 2071-2099 \\
\hline Janeiro & 28,0 & 30,2 & 31,1 & 32,6 & 2,2 & 3,1 & 4,6 \\
\hline Fevereiro & 28,7 & 30,9 & 31,8 & 33,3 & 2,2 & 3,1 & 4,6 \\
\hline Março & 28,5 & 30,7 & 31,6 & 32,1 & 2,2 & 3,1 & 3,6 \\
\hline Abril & 26,5 & 28,8 & 29,1 & 31,0 & 2,3 & 2,6 & 4,5 \\
\hline Maio & 22,6 & 26 & 27,5 & 27,9 & 3,4 & 4,9 & 5,3 \\
\hline Junho & 24,1 & 24,4 & 25,2 & 28,2 & 0,3 & 1,1 & 4,1 \\
\hline Julho & 23,4 & 24,0 & 25,5 & 26,5 & 0,6 & 2,1 & 3,4 \\
\hline Agosto & 26,3 & 27,6 & 29,1 & 29,7 & 1,3 & 2,8 & 3,4 \\
\hline Setembro & 28,6 & 30,2 & 32,8 & 33,2 & 1,6 & 4,2 & 4,6 \\
\hline Outubro & 28,6 & 31,5 & 32,8 & 33,9 & 2,9 & 4,2 & 5,3 \\
\hline Novembro & 28,6 & 31,6 & 33,9 & 34,7 & 3,0 & 5,3 & 6,1 \\
\hline Dezembro & 28,8 & 31,2 & 31,5 & 32,5 & 2,4 & 2,7 & 3,7 \\
\hline Máximo & 28,8 & 31,6 & 33,9 & 34,7 & 3,4 & 5,3 & 6,1 \\
\hline Mínimo & 22,5 & 24,0 & 25,2 & 26,5 & 1,5 & 2,7 & 4,0 \\
\hline Média & 26,9 & 28,9 & 30,2 & 31,3 & 2,0 & 3,3 & 4,4 \\
\hline
\end{tabular}

Com relação aos valores mínimos da temperatura do ar (Tabela 12), o mês de agosto ficou com maior aumento $\left(4,1^{\circ} \mathrm{C}\right)$ e o mês de maio com o menor aumento $\left(0,6^{\circ} \mathrm{C}\right)$.

Tabela 12. Valores Mínimos de temperatura mensal por intervalo de tempo.

\begin{tabular}{lcccccccc}
\hline \multicolumn{3}{c}{ Valores mínimos de temperaturas mensais } & \multicolumn{3}{c}{ Anomalias } \\
\cline { 1 - 4 } & $1961-1990$ & $2011-2040$ & $2041-2070$ & $2071-2099$ & $2011-2040$ & $2041-2070$ & $2071-2099$ \\
\hline Janeiro & 17,4 & 18,5 & 19,1 & 20,7 & 1,1 & 1,7 & 3,3 \\
Fevereiro & 18,0 & 19,0 & 19,6 & 20,6 & 1,0 & 1,6 & 2,6 \\
Março & 17,7 & 17,0 & 19,6 & 20,7 & $-0,7$ & 1,9 & 3,0 \\
Abril & 13,4 & 14,9 & 16,1 & 15,1 & 1,5 & 2,7 & 1,7 \\
Maio & 10,4 & 10,8 & 13,2 & 11 & 0,4 & 2,8 & 0,6 \\
Junho & 6,9 & 9,7 & 9,9 & 10,6 & 2,8 & 3,0 & 3,7 \\
Julho & 6,4 & 7,0 & 9,1 & 7,6 & 0,6 & 2,7 & 1,2 \\
Agosto & 5,9 & 4,8 & 8,9 & 10 & $-1,1$ & 3,0 & 4,1 \\
Setembro & 9,0 & 10,2 & 9,8 & 12,1 & 1,2 & 0,8 & 3,1 \\
Outubro & 10,5 & 11,8 & 12,6 & 13,6 & 1,3 & 2,1 & 3,1 \\
Novembro & 14,4 & 15,9 & 14,6 & 17,8 & 1,5 & 0,2 & 3,4 \\
Dezembro & 15,9 & 17,1 & 19,1 & 18,9 & 1,2 & 3,2 & 3,0 \\
\hline Mínimo & $\mathbf{5 , 9}$ & $\mathbf{4 , 8}$ & $\mathbf{8 , 9}$ & $\mathbf{7 , 6}$ & $\mathbf{- 1 , 1}$ & $\mathbf{3 , 0}$ & $\mathbf{1 , 7}$ \\
\hline Média & $\mathbf{1 2 , 2}$ & $\mathbf{1 3 , 1}$ & $\mathbf{1 4 , 3}$ & $\mathbf{1 5 , 6}$ & $\mathbf{0 , 9}$ & $\mathbf{2 , 1}$ & $\mathbf{3 , 4}$ \\
\hline
\end{tabular}




\section{5. Índice de seca}

A taxa de intensidade de chuva (ou de seca) foi extraída e classificada em uma escala de intensidade como normais (N), altas (seca (S), muito seca (MS), chuvosa (C), muito chuvosa (MC) ou intensas (extremamente seca (ES), extremamente chuvosa (EC). As Figuras 11, 12 e 13 mostram a ocorrência destas taxas de chuvas, para os três intervalos de tempo futuro.

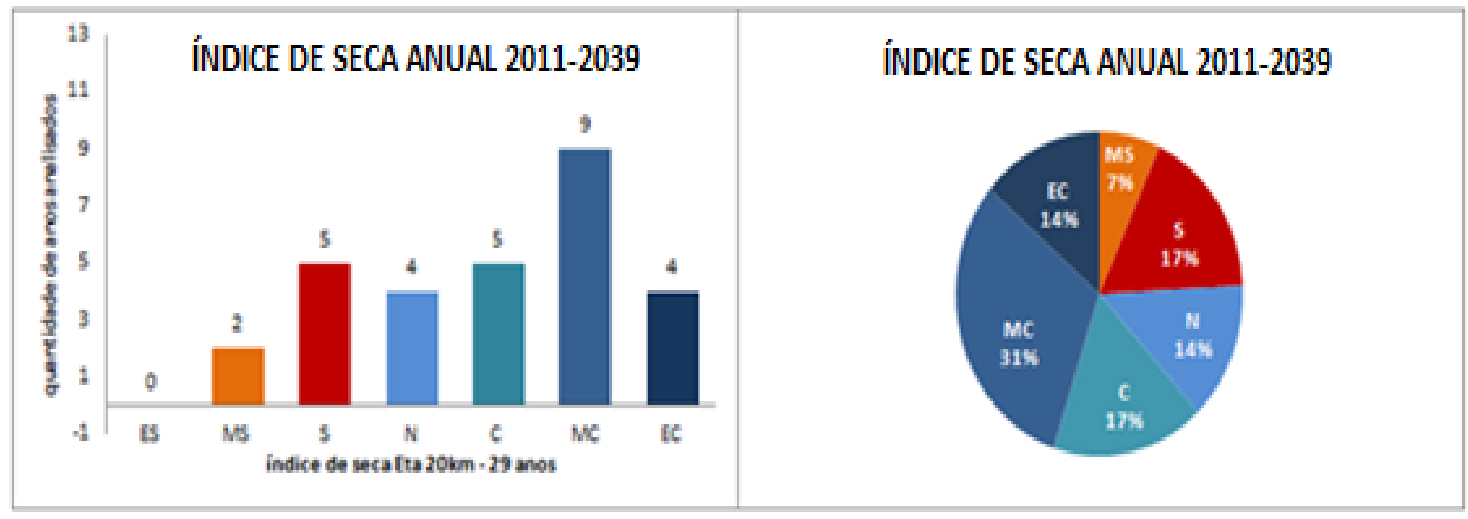

Figura 11. Índice de seca anual para o intervalo 2011-2040. Normais (N), altas (seca (S), muito seca (MS), chuvosa (C), muito chuvosa (MC) ou intensas (extremamente seca (ES), extremamente chuvosa (EC).

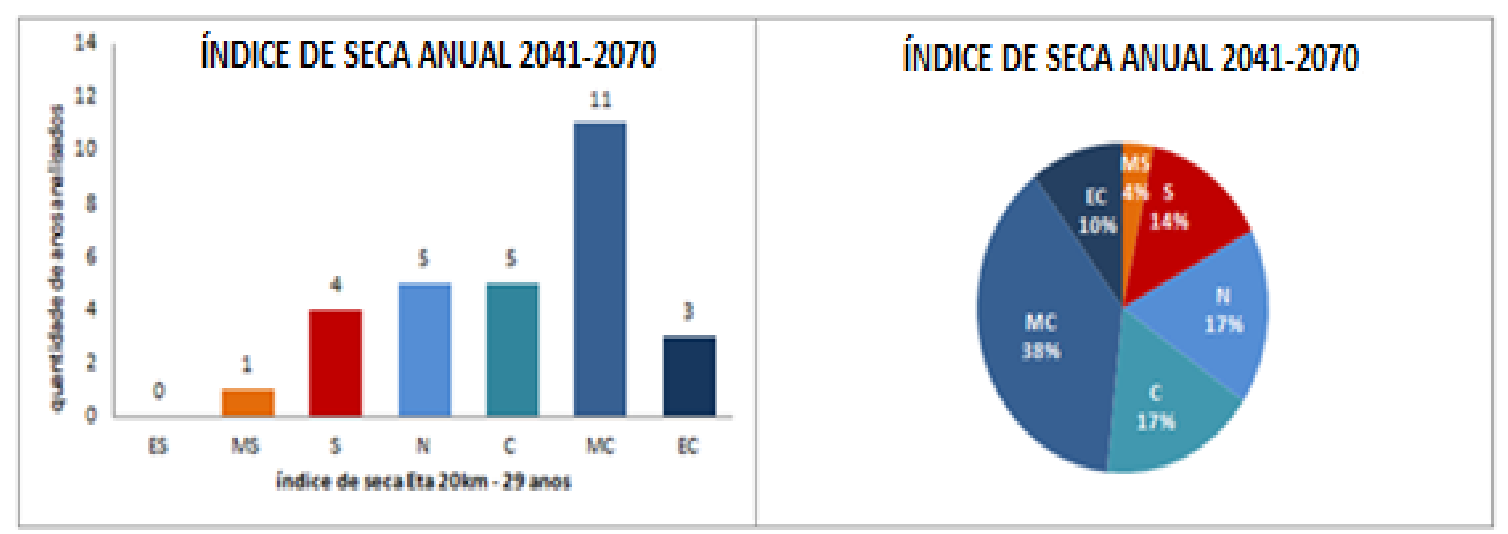

Figura 12. Índice de seca anual para o intervalo 2041-2070. Normais (N), altas (seca (S), muito seca (MS), chuvosa (C), muito chuvosa (MC) ou intensas (extremamente seca (ES), extremamente chuvosa (EC).

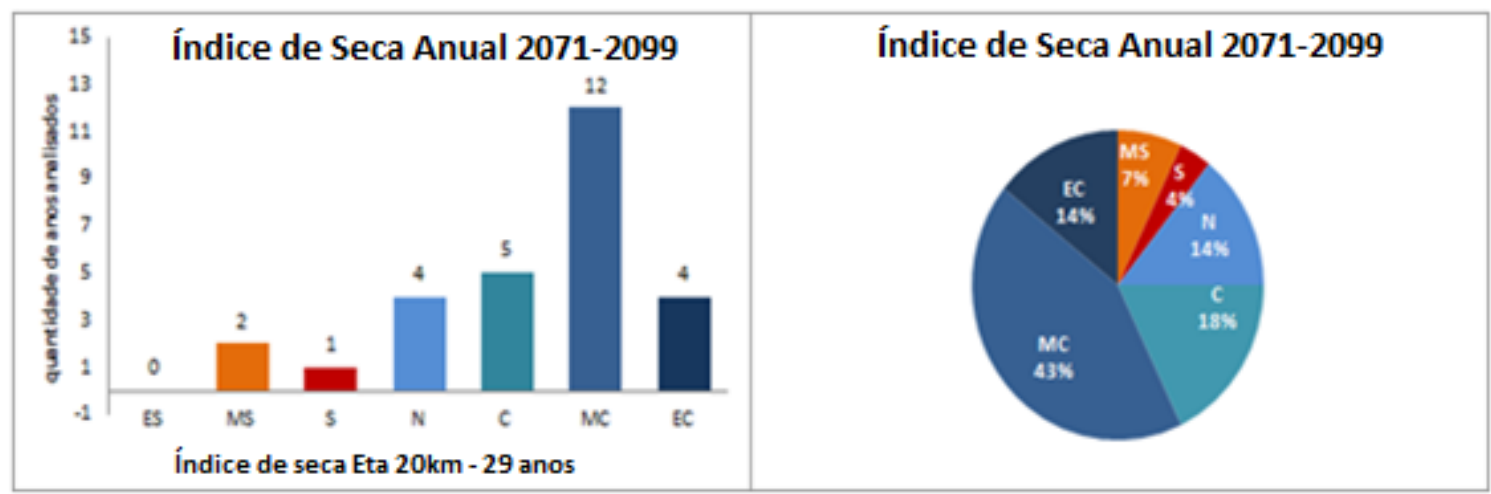

Figura 13. Índice de seca anual para o intervalo 2071-2099. Normais (N), altas (seca (S), muito seca (MS), chuvosa (C), muito chuvosa (MC) ou intensas (extremamente seca (ES), extremamente chuvosa (EC). 
Nas três séries temporais analisadas, observa-se que mais da metade dos anos possui anos chuvosos $(\mathrm{C})$, muito chuvosos $(\mathrm{MC})$ ou extremamente chuvosos $(\mathrm{EC})$ em relação à série simulada do passado (baseline), indicando chuvas acima do valor médio. Outro ponto interessante a ser abordado é que o índice de muito seca (MS) também é maior no último intervalo de tempo, indicando que, apesar de chover mais na maior parte dos anos, haverá anos muito secos, indicando uma maior variabilidade da precipitação. O índice também foi aplicado sazonalmente e obteve-se, que a estação com maior intensidade da taxa de precipitação acima do normal, foi o verão da terceira série temporal (2041-2070), com 75\% dos anos analisados. O inverno (junho, julho e agosto) de 2041-2069 foi a estação que ocorreu o maior índice extremamente chuvoso (EC), com 35\% dos anos analisados, enquanto a primavera, desta mesma série, foi a estação com a maior taxa de índice de seca $(\mathrm{S})$, ao redor de $48 \%$ entre extremamente seco (ES), muito seco (MS) e seco (S) (Tabela 13).

Tabela 13. Índice de seca sazonal. Normais (N), altas (seca (S), muito seca (MS), chuvosa (C), muito chuvosa (MC) ou intensas (extremamente seca (ES), extremamente chuvosa (EC).

\begin{tabular}{cccc}
\hline Outono & $2011-2040$ & $2041-2070$ & $2071-2099$ \\
\hline ES & 1 & 0 & 0 \\
MS & 0 & 2 & 2 \\
S & 4 & 5 & 1 \\
N & 8 & 8 & 9 \\
C & 7 & 6 & 10 \\
MC & 5 & 2 & 3 \\
EC & 4 & 6 & 4 \\
\hline Inverno & $2011-2040$ & $2041-2070$ & $2071-2099$ \\
\hline ES & 0 & 0 & 0 \\
MS & 3 & 4 & 2 \\
S & 7 & 7 & 6 \\
N & 6 & 4 & 8 \\
C & 4 & 3 & 4 \\
MC & 3 & 1 & 4 \\
EC & 7 & 10 & 5 \\
\hline Primaver & $2011-2040$ & $2041-2070$ & $2071-2099$ \\
\hline ES & 2 & 3 & 1 \\
MS & 2 & 3 & 0 \\
S & 8 & 8 & 4 \\
N & 7 & 4 & 7 \\
C & 3 & 3 & 4 \\
MC & 5 & 6 & 7 \\
EC & 2 & 2 & 6 \\
\hline Verão & $2011-2040$ & $2041-2070$ & $2071-2099$ \\
\hline ES & 1 & 0 & 0 \\
MS & 2 & 1 & 0 \\
S & 5 & 1 & 5 \\
N & 6 & 6 & 9 \\
C & 6 & 10 & 5 \\
MC & 5 & 4 & 5 \\
EC & 4 & & \\
\hline & & & \\
\hline
\end{tabular}




\subsection{Dados de precipitação diária superior a $1 \mathrm{~mm} /$ dia.}

Analisando a variação de dias de precipitação superior a $1 \mathrm{~mm}$, índice pluviométrico que indica efetividade de chuva, os resultados para o intervalo de tempo de 2071-2099 apresentam um aumento, aproximadamente, de 5 dias em relação ao clima do passado (Figura 14). A Tabela 14 mostra que o número de dias de chuva é um parâmetro bem variável, com valores entre 149 dias (ano 2091) e 214 dias (ano 2088).

Tabela 14. Dias com mais de 1mm de precipitação diária para o intervalo de tempo 2071-2099.

\begin{tabular}{ccccccccccc}
\hline Ano & 2071 & 2072 & 2073 & 2074 & 2075 & 2076 & 2077 & 2078 & 2079 & 2080 \\
Dias & 182 & 203 & 198 & 166 & 178 & 158 & 186 & 175 & 152 & 171 \\
\hline Ano & 2081 & 2082 & 2083 & 2084 & 2085 & 2086 & 2087 & 2088 & 2089 & 2090 \\
Dias & 210 & 185 & 193 & 165 & 168 & 176 & 170 & 214 & 164 & 159 \\
\hline Ano & 2091 & 2092 & 2093 & 2094 & 2095 & 2096 & 2097 & 2098 & 2099 & 2100 \\
Dias & 149 & 183 & 161 & 173 & 174 & 175 & 165 & 212 & 189 & \\
\hline
\end{tabular}

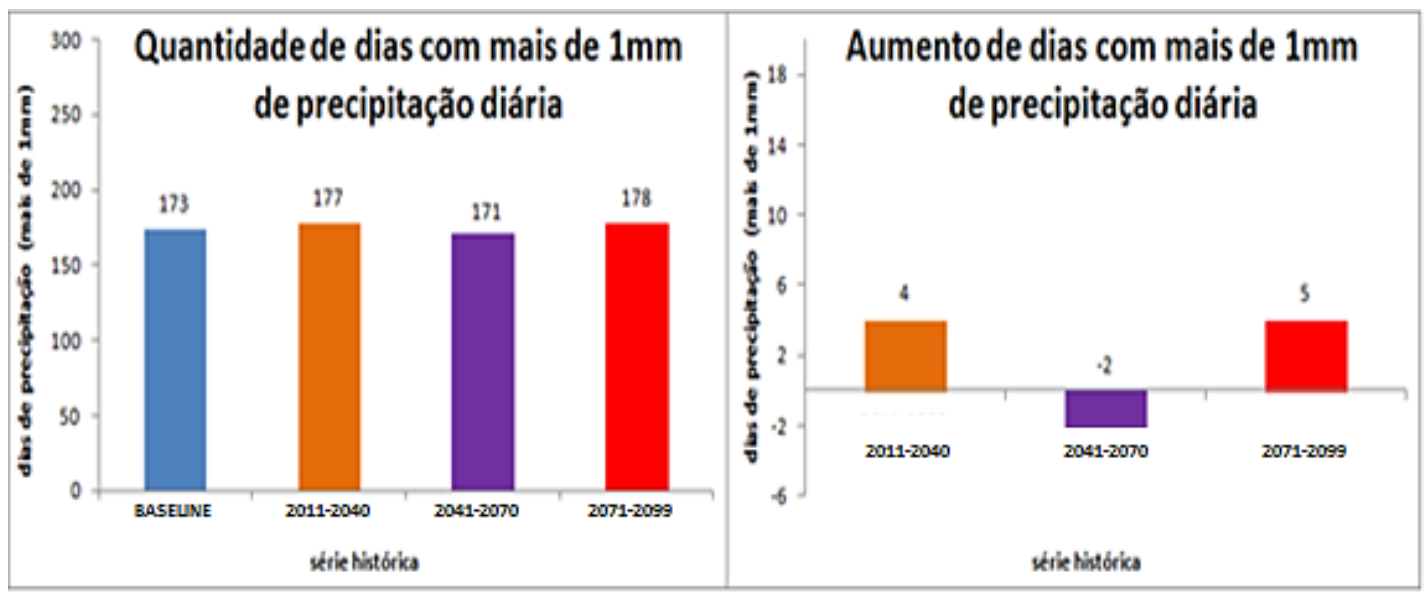

Figura 14. Quantidade média e aumento médio de dias com mais de $1 \mathrm{~mm}$ de precipitação.

Os resultados mostram que a quantidade de dias com chuvas maiores de $1 \mathrm{~mm}$ vai aumentar (em apenas 5 dias) o número do passado (baseline), sendo que, no total anual de precipitação, este aumento é maior. Isto significa que as chuvas que ocorrerão deverão ser mais intensas, o que poderá ser um problema para a questão de enchentes e deslizamento de terras.

\subsection{Dias ininterruptos de precipitação por série temporal}

Os dias contínuos de chuva são uma variável importante em vários problemas ambientais, tais como hidrologia, agrometeorologia etc. Sendo assim, foi calculada a quantidade de dias com chuvas e os resultados estão presentes na Tabela 15. 
Tabela 15. Quantidade de dias ininterruptos de precipitação por intervalo de tempo.

\begin{tabular}{|c|c|c|c|c|}
\hline Dias & $1961-1990$ & 2011-2040 & 2071-2099 & 2041-2070 \\
\hline 3 & 208 & 189 & 192 & 178 \\
\hline 4 & 144 & 140 & 112 & 145 \\
\hline 5 & 83 & 86 & 79 & 84 \\
\hline 6 & 56 & 70 & 78 & 145 \\
\hline 7 & 54 & 47 & 52 & 35 \\
\hline 8 & 33 & 37 & 41 & 25 \\
\hline 9 & 29 & 22 & 18 & 24 \\
\hline 10 & 22 & 18 & 11 & 14 \\
\hline 11 & 14 & 13 & 10 & 13 \\
\hline 12 & 14 & 8 & 9 & 9 \\
\hline 13 & 2 & 8 & 12 & 16 \\
\hline 14 & 5 & 4 & 7 & 8 \\
\hline 15 & 4 & 4 & 9 & 8 \\
\hline 16 & 0 & 4 & 3 & 3 \\
\hline 17 & 1 & 5 & 1 & 3 \\
\hline 18 & 2 & 4 & 2 & 1 \\
\hline 19 & 0 & 2 & 2 & 2 \\
\hline 20 & 1 & 1 & 1 & 1 \\
\hline 21 & 1 & 2 & 2 & 1 \\
\hline 22 & 1 & 0 & 2 & 1 \\
\hline 23 & 1 & 1 & 1 & 0 \\
\hline 24 & 2 & 0 & 0 & 1 \\
\hline 25 & 0 & 1 & 0 & 2 \\
\hline 26 & 2 & 1 & 0 & 0 \\
\hline 27 & 0 & 1 & 1 & 0 \\
\hline 28 & 0 & 0 & 1 & 0 \\
\hline Total & 679 & 668 & 646 & 719 \\
\hline
\end{tabular}

Pode-se observar um aumento da quantidade total de dias ininterruptos de chuva na série temporal 2041-2070, porém nas séries 2011-2040 e 2071-2099 houve um decréscimo. As maiores porcentagens ocorreram para 3, 4, 5 e 6 dias totalizando $73 \%$ das incidências. A incidência de até 15 dias ficou por volta de 660 casos, totalizando 97\% (Figura 15). Os aumentos expressivos destes dias ficaram nos casos com seis dias e 13 dias. A partir de 13 dias praticamente há um leve aumento de casos. Para Ayres (2010) o total de dias de permanência de chuva na região do Vale do Paraíba registrou, no máximo em 16 dias, contudo neste trabalho foram registradas projeções de até 28 dias (Tabela 15).

\subsection{Intensidade de precipitação por série temporal}

Uma classificação do critério quantitativo de chuva (ausente, fraca, moderada, forte e intensa) pelo método dos "percentis" (Figura 15) e os resultados mostraram um aumento de dias com precipitação forte e moderada para todas as séries, sendo que, para a série 20412070, houve também aumento na precipitação intensa. Este resultado, coerente com o aumento do número de dias de chuva ininterrupto, indica que o clima futuro apresentará chuvas mais intensas. 


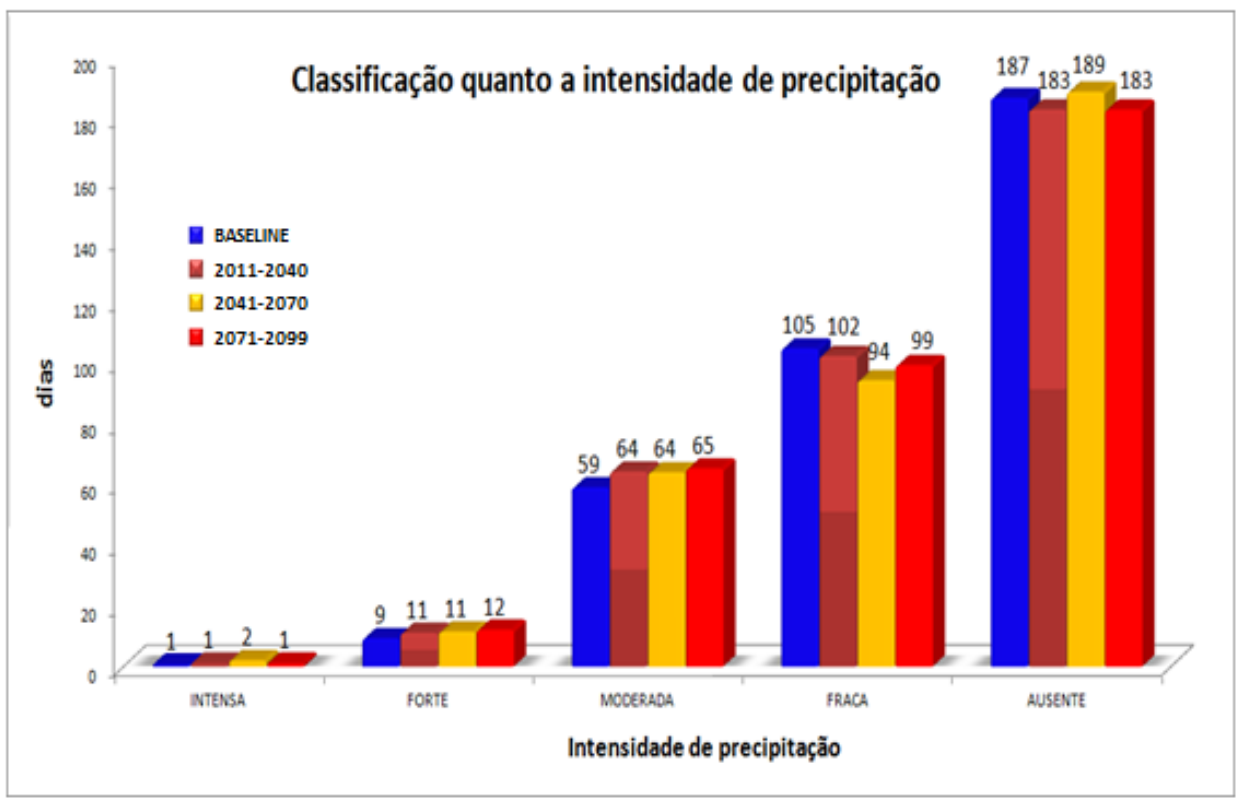

Figura 15. Intensidade de precipitação por série temporal.

\section{CONCLUSÃO}

As simulações climáticas para a região do Vale do Paraíba mostram de forma geral um aumento de temperatura do ar de $3,6^{\circ} \mathrm{C}$ e um aumento de $231 \mathrm{~mm}$ na precipitação acumulada para a escala de tempo anual, sendo este último devido aumento de dias com precipitação forte e moderada que associado ao número de dias de chuva ininterrupto, indica que o clima futuro apresentará chuvas mais intensas.

\section{REFERÊNCIAS}

AYRES, A. C. Variabilidade e desastres naturais da região do Vale do Paraíba/SP: Passado e Futuro. 2010. 89f. Dissertação (Mestrado em Ciências Ambientais) Universidade de Taubaté, Taubaté, 2010.

BREIMAN, L. Statistic: with a view toward applications. Boston: Houghton Mifflin Company, 1973. 399 p.

CONFALONIERI, U. E. C. Variabilidade climática, vulnerabilidade social e saúde no Brasil. Terra Livre, ano 19, v. 1, n. 20, p. 193-204, 2003.

COSTA, A. O.; SALGADO, C. M.; DINALI, Y. T. Caracterização da precipitação no médio vale do rio Paraíba do Sul Fluminense (RJ). Revista Geonorte, v. 2, n. 5, p. 10001013, 2012.

FISCH, G. Caracterização climática e balanço hídrico de Taubaté (SP). Revista Biociências, v. 1,n. 1, p. 81-90,1995.

FISCH, G. Distribuição da precipitação em Taubaté, Vale do Paraíba (SP). Revista Biociências, v. 5, n. 2, p. 7-11, 1999.

GOIS, G.; SILVA JUNIOR, J. L. C.; SILVA, J. S. Identificação dos períodos secos e chuvosos em algumas localidades de Alagoas através do Método dos Quantis. In: SEMINÁRIO DE BIOMETEOROLOGIA, 1., 2007, Maceió. Atmosfera e Sociedade Maceió: UFAL, 2007. 
HORIKOSHI, A. S.; FISCH, G. Balanço hídrico atual e simulações para cenários climáticos futuros no Município de Taubaté, SP, Brasil. Revista Ambiente \& Água, v. 2, n. 2, p. 33-46, 2007. http://dx.doi.org/10.4136/ambi.agua.25

INSTITUTO BRASILEIRO DE GEOGRAFIA E ESTATÍTICA - IBGE. Censo Demográfico 2010. Rio de Janeiro, 2010.

INSTITUTO DE PESQUISA ECONÔMICA APLICADA - IPEA. O comércio internacional e sustentabilidade socioambiental no Brasil. 2011. Disponível em: https://goo.gl/ozpXRB Acesso em: 2012.

MARENGO, J. A. Água e mudanças climáticas. Estudos Avançados, v. 22, n. 63, p.1-2, 2008. http://dx.doi.org/10.1590/S0103-40142008000200006

MARENGO, J. A.; TOMASELLA, J.; ALVES, L. M.; SOARES, W.; RODRIGUEZ, D. A. The drought of 2010 in the context of historical droughts in the Amazon region. Geophysical Research Letters, v. 38, n. $12,2011$. http://dx.doi.org/10.1029/2011GL047436

MORAES, M. P. C. Análise da variabilidade pluvial na unidade de gerenciamento de recursos hídricos do Paraíba do Sul (UGHRI-2). Revista Brasileira de Climatologia, v. 14, p. 98-108, 2014. http://dx.doi.org/10.5380/abclima.v14i1.36536

NUNES, L. H.; CALBETE, N. O. Variabilidade pluviométrica no Vale do Paraíba Paulista. In: CONGRESSO BRASILEIRO DE METEOROLOGIA, 11., 2000, Rio de Janeiro. Anais... Rio de Janeiro: SBMET, 2000.

PAINEL INTERGOVERNAMENTAL SOBRE MUDANÇAS CLIMÁTICAS - IPCC. Quarto Relatório de avaliação do IPCC. 2007. Disponível em: http://www.mct.gov.br/clima/ciencia/relatori.html. Acesso em: 20 maio 2012.

PAINEL INTERGOVERNAMENTAL SOBRE MUDANÇAS CLIMÁTICAS - IPCC. Grupo de Trabalho do Quinto Relatório de avaliação do IPCC. 2013. Disponível em: http://www.ipcc.ch. Acesso em: 2 mar. 2014.

SILVA, C. M. Avaliação do comportamento do regime pluviométrico na escala de tempo diária em Taubaté, Vale do Paraíba - SP. 2011. Dissertação (Mestrado em Ciências Ambientais) - Departamento de Ciências Agrárias, Universidade de Taubaté, Taubaté, 2011.

VIEIRA JÚNIOR, P. A.; DOURADO NETO, D.; CHOW, S. C.; MARTIN, T. N. Previsões meteorológicas do Modelo Eta para subsidiar o uso de modelos de previsão agrícola no Centro-Sul do Brasil. Ciência Rural, v. 39, n. 2, p. 412-420, 2009.

VILARON, M. A.; FISCH, G. Caracterização do início do período chuvoso no Vale do Paraíba paulista. Revista Ambiente \& Água, v. 8, p. 36-49, 2013. http://dx.doi.org/10.4136/ambi-agua.1254

XAVIER, T. M. B. S.; SILVA, J. F.; REBELlO, E. R. G. A técnica dos quantis e suas aplicações em meteorologia, climatologia e hidrologia, com ênfase para as regiões brasileiras. Brasília: Thesaurus, 2002. p. 141. 